\title{
The Correlation Between Spatial Configuration and User Satisfaction: A Case Study of an Activity-based vs a Conventional Office
}

\author{
Sarita Tiara ${ }^{\text {a }}$ A. Gamal ${ }^{\text {a,* }}$ \\ ${ }^{a}$ Department of Architecture, Faculty of Engineering, Universitas Indonesia, Depok 16424, Indonesia \\ Corresponding author: "gamal@eng.ui.ac.id
}

\begin{abstract}
Very few studies have discussed the quantitative correlation between office space configuration and user satisfaction. This research aims to provide more concrete results comparing the spatial configuration of Activity Based Office (ABO) and Conventional Offices (CO) to its users' satisfaction. Data collection is taken with sixty respondents who are ABO and CO. User satisfaction will be measured by the comfort aspect. Satisfaction assessment includes the comfort of social interaction distance and the uniformity of the workspace between colleagues, distance to office facilities, distance to the resting place, and distance to the office's informal socialize area. Metric measurements on physical distances and workspace areas between colleagues are compared to the user's subjective comfort. Objective data measurement using the calculation of metric line, and the workspace area differences, while subjective data collection of users using questionnaires. The statistical analysis that will be used is the cross-tabulation method. Cross tabulation will give an overview of the comparison between comfort level to the objective distance and workspace area differences. The study results show that the physical distance comfort of an activity point will vary according to the needs of its user preference. Comparison of spatial to the activity-based and conventional offices will also influence the perception of the uniformity of the user's workspace, and the behavior of users in the elections performs several activities within the office.
\end{abstract}

Keywords — User satisfaction; activity based office; conventional office; spatial configuration.

Manuscript received 23 Jul. 2020; revised 29 Dec. 2020; accepted 3 Feb. 2021. Date of publication 30 Apr. 2021. IJASEIT is licensed under a Creative Commons Attribution-Share Alike 4.0 International License.

\section{INTRODUCTION}

The long working hours that cause many workers to spend most of their time inside the office have changed office design to be more flexible and to adjust to user satisfaction [1]. It needs a deeper discussion about the correlation of office spatial configuration with user satisfaction being measured subjectively and objectively. Many previous studies have said that user satisfaction in the office can improve their employees' performance and productivity [2]-[5]. To improve employee satisfaction, social interactions and spatial configuration should be seen from physiological and psychological factors. The impact of physiological comfort in an office depends on the location of the user's work desk, orientation, and office layout [4]. Previous research used a qualitative method to measure user comfort and its impact on social contact, spatial comfort, and a healthy working environment [6]-[12]. However, user comfort should also be compared with measurable or quantitative results.
This research aims to provide more concrete results in comparing the activities-based and conventional office's spatial configuration. Concrete results are obtained by calculating the metric in spatial configuration and its effect on the comfort level of communication between users, performance, attitudes, and organizational culture. The result will show user satisfaction in the office. Therefore, this research aims to determine the optimal distance and the area difference in the activities-based office and conventional offices workspace that improve user's satisfaction.

Previous studies used space syntax as the most appropriate measurements for spatial configurations [13]. Space syntax is an analysis with metric measurements using lines to show circulation flow [2], [14]. Previous qualitative research discussing spatial configurations, most of the previous researchers established office interior design instruments that would affect user satisfaction. The instruments are:

- Work desk location, use of office facilities and social interactions [15]

- Privacy, proximity perception, workspace equality [3] 
- Privacy satisfaction, communication, workspace comfort [16].

This study's spatial configuration types are the conventional office (CO) layout and the activity-based office (ABO). Shahzad [17] stated that the layout of $\mathrm{CO}$ has a structurally divided space and organization division. $\mathrm{CO}$ workspace is private and can only accommodate 1 to 3 persons. The user can also adjust the temperature, lighting, and outside views of the working environment individually [10], [17]-[19]. Meanwhile, the ABO workspace has a spatial layout with a low hierarchy [20]. The ABO workspace offers a choice of space that supports user activity preferences, thus enabling the users to adjust where, when, and how to do their jobs [15], [20]-[24].

Kwon [11] and Beijer [25] provided insight into the difference in spatial configurations that affect user satisfaction. Beijer [25] said that flexible offices could reduce the privacy and concentration of its user compared to other office types. However, communication and social interactions were better when implementing a mixed and flexible office type rather than a closed office. Kwon [11] added that spatial configuration had a great influence on user satisfaction. When comparing several factors, such as privacy, territory, and concentration, the user satisfaction of the closed office type is greater than that of the open or flexible office type.

Previous user satisfaction research only discussed the instrument of spatial configurations using qualitative methods. In the meantime, research that discussed how to measure the spatial configuration only performs quantitative research, and the results were not associated with user satisfaction. The correlation of spatial configuration on the office user satisfaction should be supported by qualitative and quantitative methods so that the implementation of spatial configuration comfort can be determined objectively.

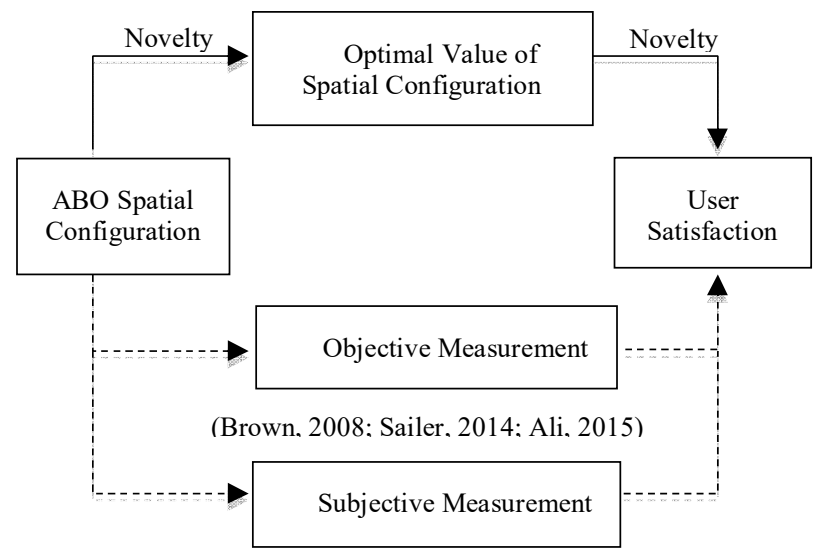

(Davies, 2008; Beijer, 2014; Zerella, 2017; Kwon, 2019)

Fig. 1 Theoretical Framework

\section{MAterial AND Methods}

Our research took place in 2 offices with different spatial configuration types so that we could compare the value of user satisfaction in different office types. We used the users of each office as our object to observe their behavior. Both offices were companies that engaged in the field of services and had approximately 50 employees. We select the subjects who will be asked randomly with assistance from the human resource department (HRD). The total respondents studied were 60 employees at the $\mathrm{CO}$ and the ABO. Subjects to be investigated were permanent officers, having their desk, having regular working hours, having a supervisor, and not a board of directors.

Qualitative data were supported by quantitative data with objective calculations that were applied to the office spatial configuration. The questionnaire was used to collect user satisfaction measurement while also calculating the distance and the objective area using. To do this, we used AutoCAD to help in collecting these qualitative data. After that, the combined data were calculated and analyzed with a crosstabulation method. The instruments that were measured were the objective value of distance and workspace area and how it affected the comfortable of the distance of someone's desk to other users' desk, distance to office facilities, distance to the rest area, distance to the place to socialize outside office hours, and convenience distance of uniform workspace office users.

\section{A. Spatial Configuration Measurement}

Measurement in a spatial configuration was represented by the flow paths of the subject's circulation to the office environment's activity area. This data was used to measure the objective value of the distance and the work area of each subject. The measured circulation path was the distance to the other users' work, the distance to the facilities supporting work productivity, the distance to the resting area, and the distance to the place of social interaction. Meanwhile, the measured work area was co-worker workspaces. After that, subjects were asked to mark the following positions in the picture: subject work desk, subject's supervisor desk, subject division area boundaries, other divisions area boundaries, meeting room that subjects usually use, frequent photocopies/printing places, a place for telephones to get more privacy, a place to relax, eat, smoke, and socialize. After the subject signifies the activity spaces under the information, the subject is asked to describe the daily circulation flow. Subjects were asked to draw using the flowchart color markers from the subject's workbench to the above activity positions.

\section{B. Questionnaires}

We used a questionnaire in the form of questions with answers that will be divided into 7 columns to collect subjective data. The answer was ranged from "Very Comfortable" to "Very Uncomfortable". The questionnaire data collection took approximately 4 - 5 hours a day for 10 people. It took 3-4 days to complete data collection in 1 office. Subject data collection was done individually and supervised by the researchers.

\section{Data Analysis}

AutoCAD was used to measure the distance and the objective area. The drawing used for the calculation of spatial configuration was a floor plan for each office floor. The distance of the subject table to the activity spaces was measured using the length of lines that indicate the value of the distance in meters. The length of the measured line was the length of the circulation path the subject passes from one 
point to another. Uniformity of the workspace was measured by the area difference of the subject's workspace with colleagues. The area's difference was calculated by the width of the worktable and the length of the distance between the table and the area behind the subject's work chair. Measurements in a closed supervisor's workspace were the room's total area that was restricted by a partition or wall. After we had measured all subject tables, a comparison of the difference in workspace could be determined.

The next step was to group the analysis of subjective data that has been collected into 7 groups according to the assessment. Value 3 was the maximum value, which represents the value "Very comfortable", while the value -3 was the smallest value that represents the value "Very uncomfortable."

Analysis using cross-tabulation were done after all data collection was over. Comparing instruments that affect distance comfort and uniformity of workspace included the objective value of distance, the objective value of the difference in the workspace area, and the type of office. After the data in the cross-tabulation table is collected, the table can be transformed into a graph to make it easier for readers to see the distribution of objective values at each comfort level.

\section{Case Context}

\section{1) Case 1-CO}

Case 1 was an office that dealt with the supply services (outsourcing) field. It was built in 2015. Case 1 was a conventional office that had its building and had a divided spatial layout. Most supervisors' workspaces were covered with partitions. Each division worked in a separate room. There was barely any space left for other activities since most of them were used to support work-related activities. It forced the users to spend their break at their desks or leave the building to spend it outside the office environment.

There were differences in the workspace area between each division and even between colleagues in the same division. It was caused by the addition of new employees and differences in job positions. Thus, we needed to measure the difference in workspace size to see the effect of workspace uniformity on user satisfaction.

Six floors are used as activities spaces for office users. Space on each floor was used differently according to the organization's position and the type of activities. There were also spaces used to support office users' activities like the prayer room and sports room. The ground floor was used for a parking lot and reception, with no workspace. The first floor was divided into a human resource division workspace, an interview room, a training room, and a discussion room. There was a boardroom for directors, a director's secretary desk, directors' staff work rooms, and large meeting rooms on the second floor. There were a financial division, cashier, division in charge of the branch office, and waiting chairs on the third floor. There were meeting rooms, IT divisions, general divisions, and marketing divisions on the fourth floor. On the fifth floor, there were a prayer room and gym.

A CO usually uses a door and a wall to separates the work area between each division. It was apparent in this case study. The office also used stairs and elevators as its vertical circulation that the users could use.

\section{2) Case $2-A B O$}

Case 2 was an office engaged in providing industrial equipment for factories or fieldwork. Case 2 was an office that had an activity-based concept or ABO. The ABO was located in its own building and it had an open layout, meaning there was no partition to separate supervisors' desk and the employees' desks. Workspace between divisions was also not divided. ABO provided spaces that support the activities for office operations and for resting. There were prayer rooms, lounges, bedrooms, meeting rooms, dining rooms, and shared office facilities.

Users in the $\mathrm{ABO}$ did activities in the designated places that support their activities so that the circulation flow varies. Work desks in ABO tended to have the same area size, but as time went by, the addition of a work desk to new employees resulted in a difference in work area size between the employees. Even the supervisors' work area size differed from each other. We needed to measure the different areas of superiors' and employee's workspaces to see the effect of work desk uniformity on user comfort.

$\mathrm{ABO}$ had 3 floors that were used for different activities. There were 2 meeting rooms on the ground floor, a reception desk, 2 division rooms, a warehouse, a parking lot, and a guesthouse. There were 3 directors' workspaces, secretary desks, meeting rooms, and dining rooms on the second floor. There were 3 meeting rooms, prayer rooms, lounges, and open workspaces consisting of financial divisions, legal divisions, personnel divisions, marketing support divisions, and marketing divisions on the third floor. Vertical circulation in the $\mathrm{ABO}$ was staircases.

\section{RESULTS AND DISCUSSION}

\section{A. Distance to fellow office users}

Previous research said that distance could affect user behavior related to communication, collaboration, and organizational culture [3]. Kabo [5] said that a distance of 25 meters could reduce interaction between office users. According to Neufert [26], the minimum distance between office users is 1.4 meters. We found out that $1.4 \mathrm{~m}$ was the standard area of individual desks and the aisle's standard width between office users' chairs that faced the opposite direction. In this study, the distance assessment of fellow office users was the distance to the supervisor, colleagues in the same division, and colleagues in a different division. Measurement of distance to office users more specifically showed a more critical relationship in office layout design that could increase user comfort.

Fig. 2 shows that the distance to supervisor's desk and comfort level. Subjects with desks there were less than 15 meters felt more comfortable in both $\mathrm{CO}$ and $\mathrm{ABO}$. Most subjects $(40 \%)$ felt comfortable with supervisors who were between 5 to 11 meters. Users who sat very close to their supervisors $(<5$ meters) felt uncomfortable. It was because it was easier for the supervisor to monitor their employees. However, 2 subjects in a $\mathrm{CO}$ felt comfortable with this situation, but 2 subjects in the $\mathrm{ABO}$ felt uncomfortable sitting more than 20 meters away from the supervisors. 


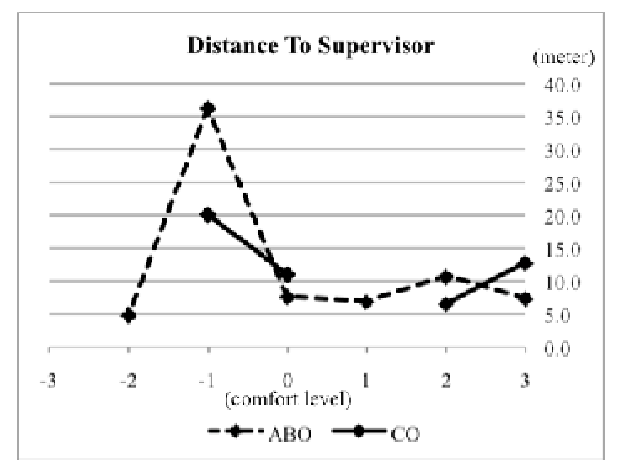

Fig. 2 Distance Measurement to Supervisor Desk and User Comfort Level Graph

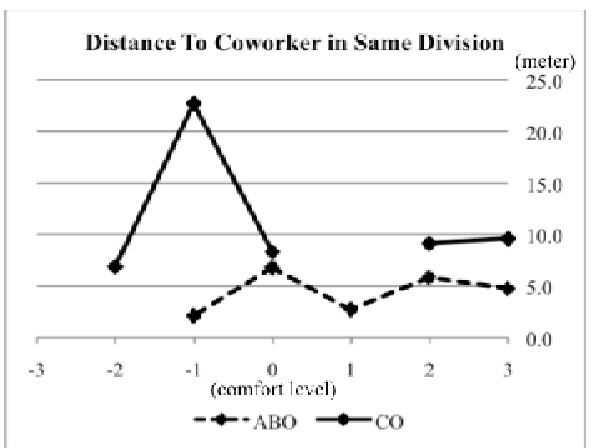

Fig. 3 Distance Measurement to Co-worker in Same Division and User Comfort Level Graph

From fig. 3, most subjects felt more comfortable if the average distance of colleague's workdesks was under eleven meters. In the ABO, there was one subject who felt neutral with a distance of over 11 meters with co-workers. In a CO, 8 subjects felt comfortable with a distance of over 11 meters, but only 1 subject felt uncomfortable with more than 20 meters distance. The ABO had a more flexible spatial layout so that the distance of colleagues in the same division could be adjusted more efficiently than $\mathrm{CO}$.

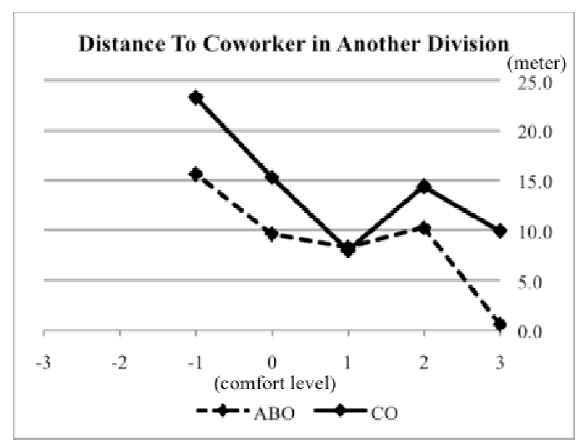

Fig 4. Distance Measurement to Co-worker in Another Division and User Comfort Level Graph

From Fig. 4, the subject felt more comfortable if the distance between other division partners was not too far away. The comfortable distance between colleagues in another division was not more than 15 meters because it was still easy for people to reach their co-workers within this distance. At a distance of 1,4 to 15 meters, many subjects felt very comfortable and comfortable. At distances above 15 meters, $\mathrm{CO}$ subjects felt uncomfortable, while at distances above 10 meters, subjects at the ABO felt uncomfortable. ABO users could cover these distances more efficiently due to the open space layout. Meanwhile, users in
CO had to travel long distances to their colleagues in other divisions.

\section{B. Distance to office facilities}

Meulenbroek [15] said that the use of office facilities could influence the activity-based office's success. Therefore, the location of office facilities and their quality can be used as an assessment of ABO. ABO has low privacy, and the concentration for telephone calls was deficient due to noises from the open office space [27]. The meeting room is at the lowest level in the choice of work locations in an ABO [15]. In this study, the assessment of the comfortable distance to the office facilities included the distance to the meeting room, shared printing facilities, and telephones. The place of activity chosen was a place that can improve the performance of its users.

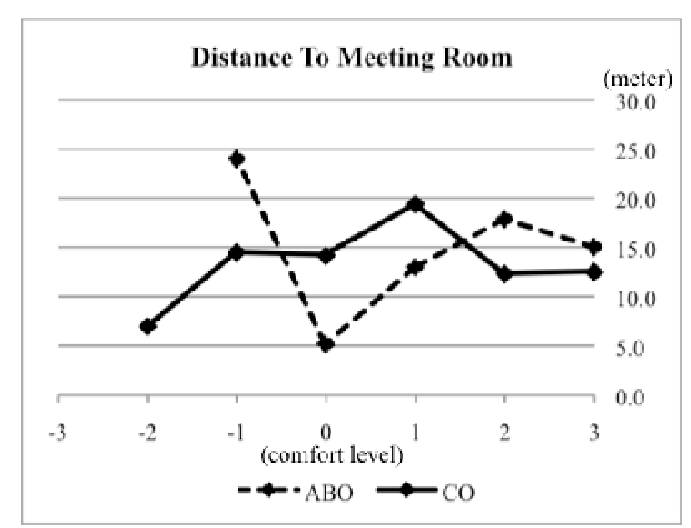

Fig. 5 Distance Measurement to Meeting Room with User Comfort Level Graph

From Fig. 5, the subjects felt more comfortable if the distance of the meeting room was far from their desk. The average subject felt more comfortable if the distance of the meeting room was above 10 meters. Average subjects in ABO felt comfortable at a distance of 15 to 20 meters. In CO, average subjects felt comfortable at a distance of 10 to 20 meters. In the open layout office, louder noises would disturb the users if the meeting room was near the subjects' working area. $\mathrm{CO}$ users who work in a close layout office feel more comfortable if the meeting room is within their visual range and is not too far from their desk. Collaboration is easier to be done in that way.

Fig. 6 shows the analysis of the user comfort to the shared printing facility distance. Most subjects were at a distance of 5 meters to 10 meters away from the printer. There were 20 subjects in $\mathrm{CO}$ and 11 subjects in $\mathrm{ABO}$ who were comfortable at a distance of 5 meters to 10 meters. At the $\mathrm{ABO}$, the printing facility was in the middle of an open workspace so that the average subject felt uncomfortable sitting at the above 10 meters away from the printing facility. Meanwhile, $\mathrm{CO}$ set their printers at specific points in each division room. There were a couple of subjects who felt uncomfortable being less than 5 meters from the printing facility. A distance that was too close to the printing facility will cause discomfort. There were CO subjects that worked side by side with shared printing facilities who felt uncomfortable because the workspace became more crowded. 


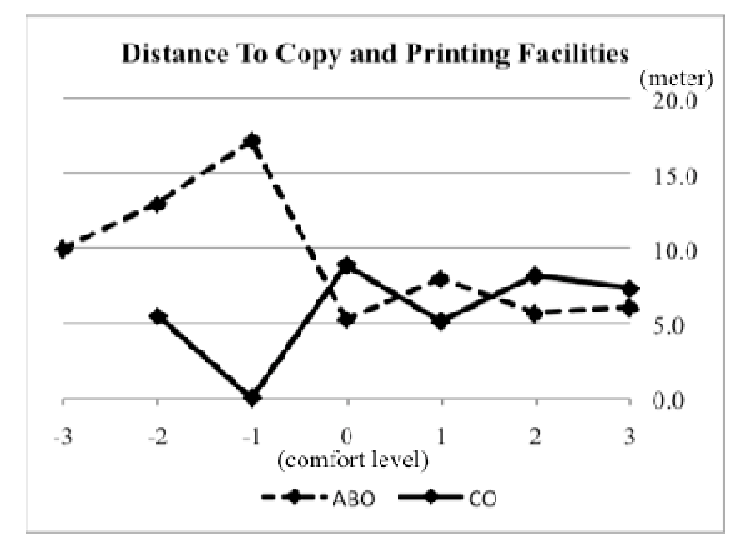

Fig. 6 Distance to Copy and Printing Facilities with User Comfort Level Graph

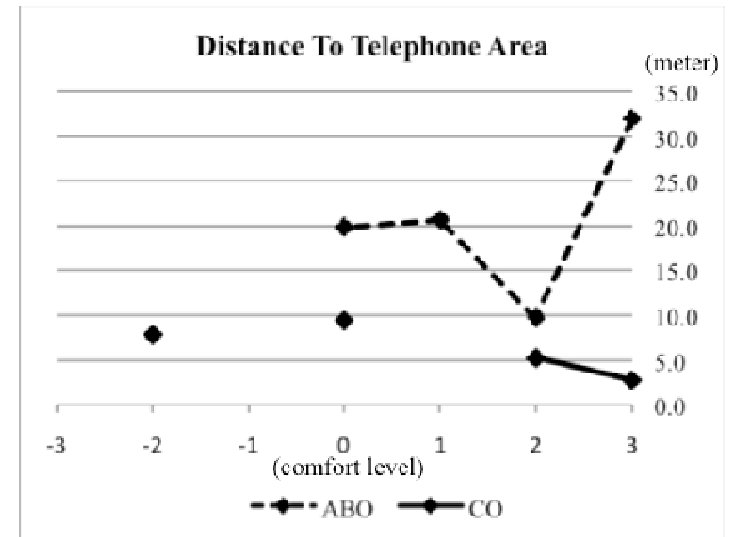

Fig. 7 Distance to Telephone Area with User Comfort Level Graph

Fig. 8 shows the graph of user comfort to the phone booth distance. Office users who could make a call from their work desk felt more comfortable compared to others. Most CO users felt comfortable using their desks to make a phone call, while $\mathrm{ABO}$ users have to leave their workplaces to get a quieter place to make a phone call. The total numbers of subjects who felt very comfortable and comfortable making a phone call at their desk in $\mathrm{CO}$ were 18 subjects, while $\mathrm{ABO}$ users were only 10 subjects. The average subjects felt comfortable with a distance of 10 to 30 meters to find a quieter place for a phone call in $\mathrm{ABO}$, while the average subjects at $\mathrm{CO}$ felt uncomfortable with the distance of 5 to 10 meters. The results showed that $\mathrm{CO}$ users were more convenient for making a phone call at their work desks, while $\mathrm{ABO}$ users must leave their desk and moved from 10 meters to 30 meters to have a quiet place for the phone call.

\section{Distance to the resting place in the office}

Recent research suggested that employees who worked in an office would spend most of their daily time in the office [1]. The balance of life and work is one factor that influences office users' satisfaction [12]. O'Donnell [12] said that a healthy work environment affected its users' mental health and comfort. Previous researchers had said that an unhealthy working environment would cause users to feel depressed, fatigued, and even insomniac [28]. This research determines the distance between the comfort of the prayer room and the sleeping area which also worked as a break room in both offices.

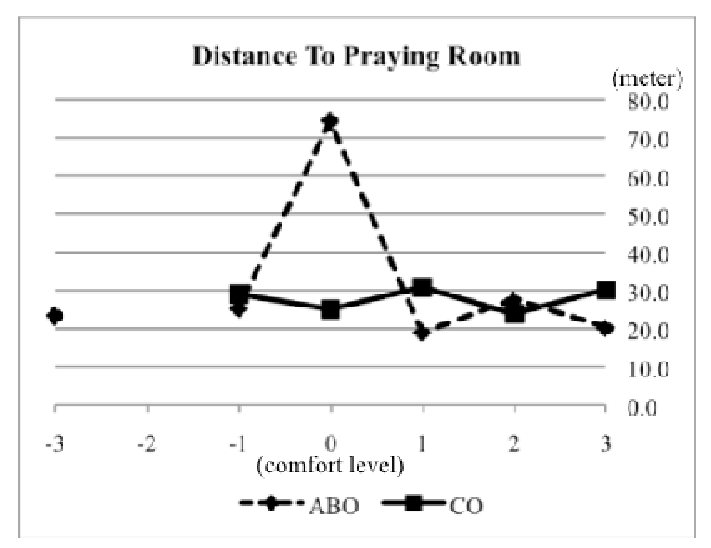

Fig. 8 Distance to Praying Room with User Comfort Level Graph

Fig. 8 shows the distance to the praying room and comfort level. Subjects were more comfortable if the distance of the prayer room was far from their desks. There were 52 Muslims subjects in the office. Most subjects felt comfortable at a distance of 20 to 30 meters from the prayer room. 13 subjects felt comfortable at a distance of 20 to 30 meters, and 11 subjects felt comfortable at 30 to 40 meters. The difference in the type of office to the prayer room's distance did not seem significant because the distance between the subject's work desk and the prayer room was almost similar. One subject in a $\mathrm{CO}$ sat less than 5 meters away from the prayer room, yet he used a space near his desk to pray. Conventional closed offices have a higher privacy level, so users feel more comfortable praying in a space near their work desk, even though it is not a space for praying.

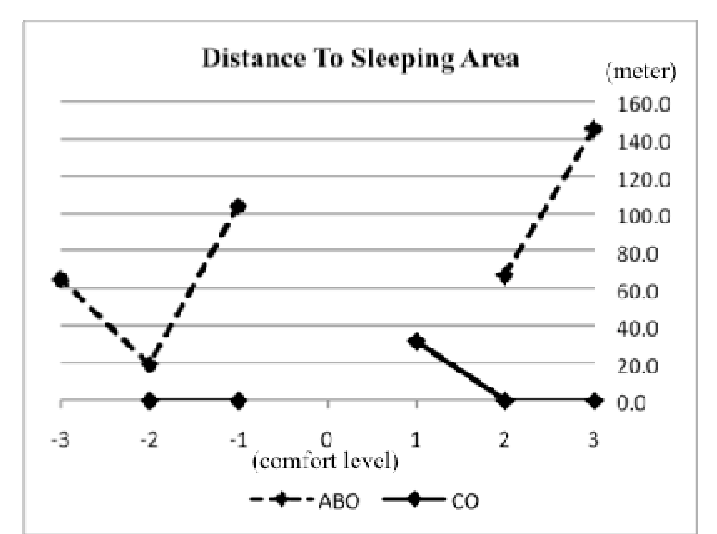

Fig. 9 Distance to Sleeping Area with User Comfort Level Graph

Fig. 9 shows the distance to the sleeping area and comfort level. Data collection of comfortable distance to the sleeping area shows that only 16 users rested and even slept in the office. Subjects were more comfortable if the resting area was far from their desk. In a $\mathrm{CO}, 4$ subjects felt comfortable, and 2 subjects felt uncomfortable sleeping at their desk. The ABO provided a sleeping area for its users, but it was far from the employee's workspace. Four subjects felt comfortable, and 2 subjects felt uncomfortable with a distance above 60 meters to the sleeping area. The workspace in $\mathrm{CO}$ was more concealed since there was a divider to the supervisor's work desk. The space between divisions was also separated, so the users felt more comfortable taking their desks' break. Users in the $\mathrm{ABO}$ felt more comfortable resting in the further resting area for 
sleeping because the open workspace layout had less privacy. The availability of sleeping space could determine the user's comfort, so 60 meters was the optimal distance to design a place for a sleeping area in the ABO.

\section{Distance to the informal socializing area}

Previous research said that social contact is one factor that influences user satisfaction [4], [8], [25]. Social contact in this research means the informal social interaction that users have during office breaks or their daily interactions [4]. Meulenbroek [15] said that office users frequently use eating places to interact socially during office breaks. Elmahadi [8] had conducted research that discussed the spaces commonly used by office users for social interaction. Users in offices with open layouts usually interact in dining rooms, office yards, work desks, and prayer rooms. Users in a closed office interact in a prayer room, living room, and individual workspace. This research discussed the distance of the user's comfort in the dining room, smoking area, and other social spaces that were used for social interaction.

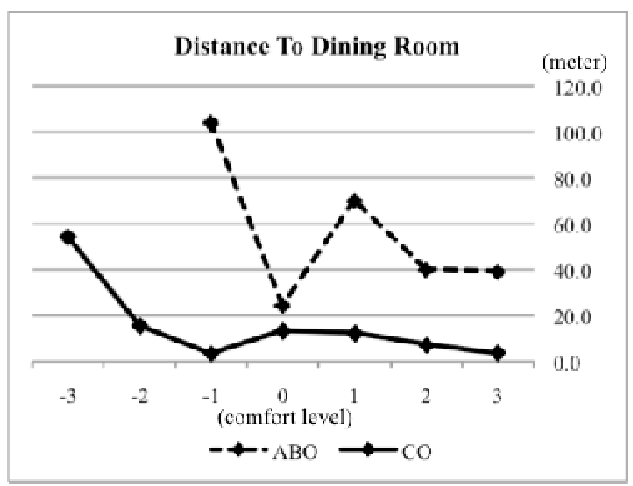

Fig. 10 Distance to Dining Room with User Comfort Level Graph

Fig. 10 shows the distance to the dining room and user comfort. Subjects were more comfortable if the dining room was closer to their desk. Users in the ABO provided with a dining room felt comfortable at a distance of 40 to 70 meters. No ABO users ate at their desks. $\mathrm{CO}$ did not provide a dining room, so users ate at their desks. CO users also used discussion rooms or meeting rooms for eating, so the average distance of comfort was below 20 meters. Three CO users felt uncomfortable eating at their work desks, while 4 ABO users felt uncomfortable with a considerable distance ( $<90$ meters) from their desks to the cafeteria outside the office environment. Based on the average comfort of users who used the dining room, the optimal distance to design a place to eat in the office was 20 to 50 meters.

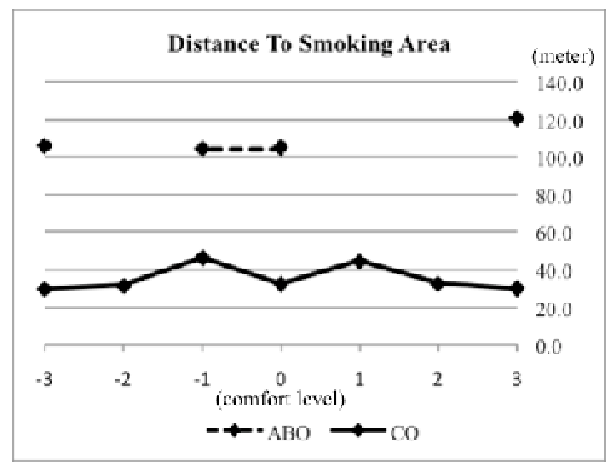

Fig. 11 Distance to Smoking Area with User Comfort Level Graph
There were only 19 subjects who are smokers in the ABO, and $\mathrm{CO}$. Users were more comfortable if the distance to the smoking area was far from their desks. They felt more comfortable with distances above 30 meters. The ABO used the office building's backyard as the smoking area, so users felt comfortable with a distance of over 90 meters. CO used parking lots in the office yard and open spaces on the rooftop as smoking areas about 25 to 50 meters away from their desks. 4 subjects said they were uncomfortable with 25 to 40 distance to the smoking area. Therefore, the distance to the smoking area should be above 40 meters from the workspace.

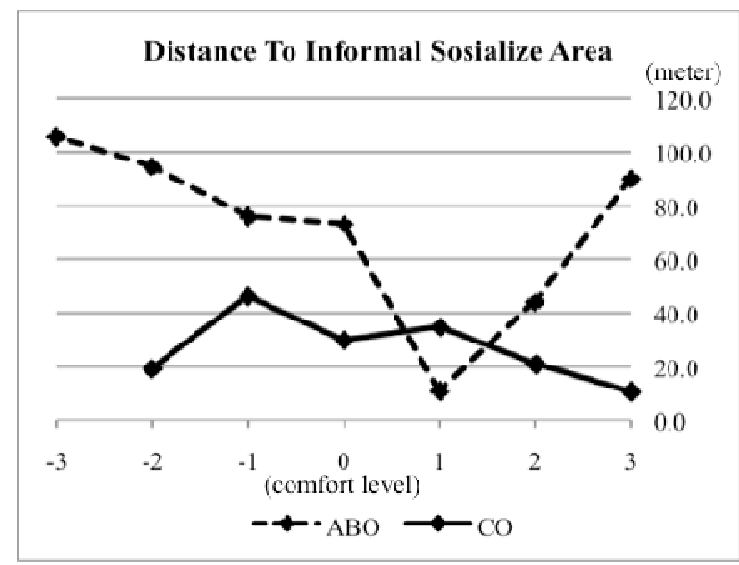

Fig. 12 Distance to Socialize with User Comfort Level Graph

From Fig. 12, the subjects were more comfortable if the socializing area was close to their desk. Most subjects felt comfortable with 10 to 40 meters distance from their desk to the socializing place. A lot of male users at the ABO socialized in the smoking area. They had to walk for more than 90 meters to socialize. They found it rather uncomfortable because it was too far. Many CO users felt comfortable at a distance of 0 to 5 meters because they socialized at their work desks. Users in the ABO socialized more in the dining room or lounge, so the subjects felt comfortable at a distance of 10 to 50 meters from their desks.

\section{E. Uniformity workspace with fellow office users}

Previous research said that uniformity of workspace among office users will positively influence behavior, organizational culture, and will increase comfort [3]. The difference in actual area size and perception of workspace in the office can be used as a symbol of differences in organization status among fellow office users, which will affect social interaction [29]. Spatial characteristics such as the use of cubicles or closed rooms and the amount of workspace can be used as symbols of position in an organization [30], while open and non-segregated office layout will result in a better perception of uniformity in the workspace [3]. This study specifically discussed the users' comfort of the different workspace area size to their boss' workspace area size, a colleague in the same division workspace area size, and the colleagues of another division workspace area size. 


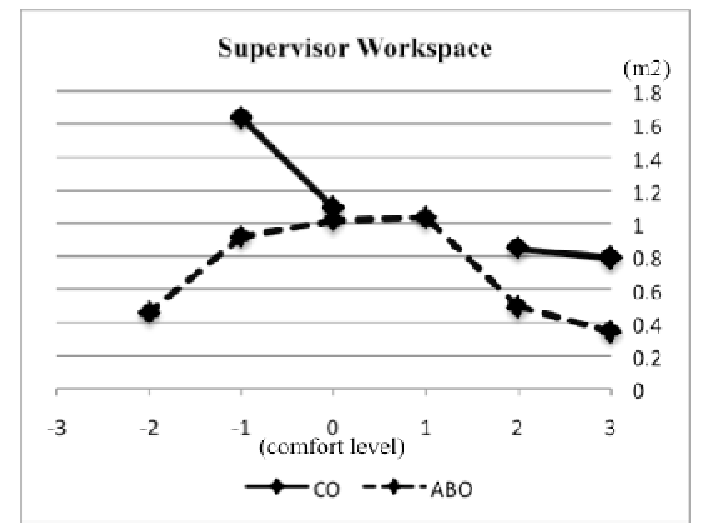

Fig. 13 Supervisor Workspace Equality Measurement with User Comfort Graph

In general, office users felt uncomfortable if there was more 1 square meter difference in size area between their workspace and their boss' workspace. Twelve subjects in the ABO felt comfortable with a difference of 0.1 to 0.8 square meters, while 14 subjects in $\mathrm{CO}$ felt comfortable with a difference of 0.8 to 1.2 square meters. Users in $\mathrm{CO}$ had more significant differences in workspace area size with supervisors compared to $\mathrm{ABO}$. The $\mathrm{CO}$ separated the supervisor's room from its employees with a partition to emphasize the supervisors' status or position. However, average office users were more comfortable if the difference was below 0.5 square meters.

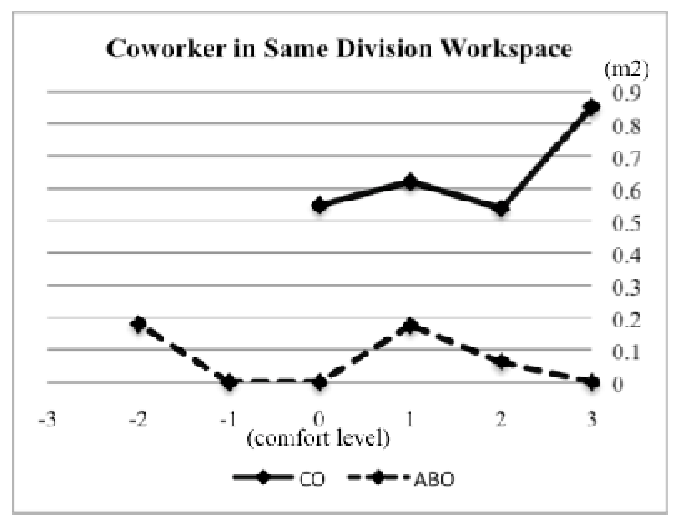

Fig. 14 Co-worker in Same Division Workspace Equality Measurement with User Comfort Graph

The workspace size difference between colleagues in the same division's workspace was mainly caused by the addition of work desks for new employees. Meanwhile, the workspace size difference between colleagues in the same division was due to changes in the old and new work desk model, not because of differences in a job position. More than $50 \%$ of subjects had the same table area as their peers. Eleven subjects in a $\mathrm{CO}$ felt comfortable even though there was more than one-meter difference in workspace size. Two subjects in the ABO felt uncomfortable even though every user had the same workspace area size. It means the workspace's uniformity is not too significant when the users are from the same job position and division.

The workspace area size difference between colleagues in other divisions was caused by the addition of work desks for new employees so that the difference in the workspace area size was not due to differences in a job position. Fifteen subjects in $\mathrm{CO}$ had the same workspace area size as their colleagues in other divisions and were comfortable with it.

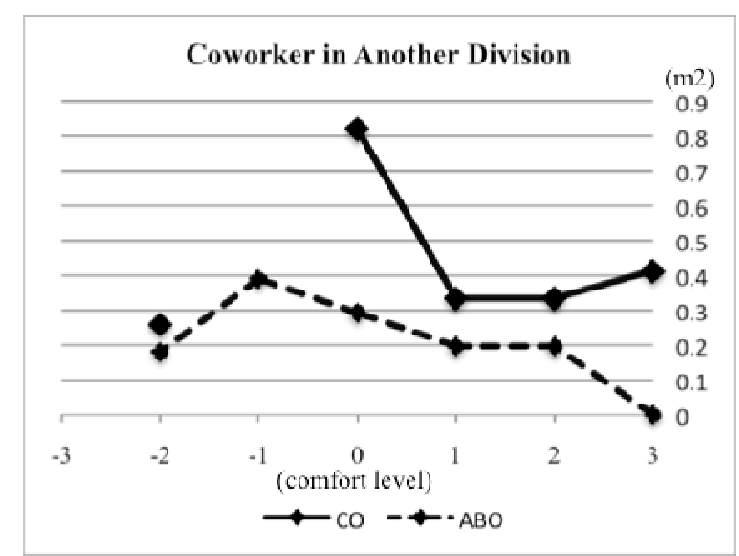

Fig. 15 Co-worker in Another Division Workspace Equality Measurement with User Comfort Level Graph

Seven subjects felt comfortable even though there were 1 to 2 square meter area size difference. In $\mathrm{CO}$, each division's area is covered by a wall, so the user's perception of the workspace's uniformity becomes biased. ABO that did not separate space between divisions and had an open layout. The subjects' perception of uniformity of workspace was more pronounced. Subjects in the ABO were more comfortable if the difference workspace area size with other divisions was not more than 0.5 square meters.

\section{CONCLUSION}

In this study, objective measurements and comparisons of office types were carried out to measure office users' comfort levels. Interaction between office users can be influenced by work desk distance, uniformity of workspace, and informal socializing venues. The distance between fellow users' work desk is more comfortable if they are not too far away $(<15$ meters), so communication and collaboration can be carried out easily. The workspace area size's uniformity can represent someone's position in the office's hierarchy or office's organizational structure. CO layout represents users' status and position so that the difference between the supervisor's workspace and the employees is very high ( 0.8 to $1.7 \mathrm{sqm})$. ABO users have a more negligible workspace area size difference $(0.4$ to 1 sqm), but the distance between the work desk and the supervisor becomes smaller. The close distance was not always suitable for user satisfaction because users tend to feel uncomfortable when they were sitting very close to their boss ( $<5$ meters). In calculating the distance between the socializing and dining rooms, the optimal distance is 20 to 50 meters.

User comfort can also increase productivity and health. Users feel more comfortable when work facilities that could increase productivity were not too far from the user's desk ( 5 to 10 meters). The open layout of the ABO can cause high noise levels, so the users need to leave their desks and found a quieter place to make a comfortable phone call (10 to 30 meters). $\mathrm{CO}$ has a closed layout, so the users feel comfortable making a phone call at their work desks. Meeting rooms that several people use can reduce the concentration of users who work nearby. Most users feel 
comfortable if there is a distance between their desks and the meeting room (10 to 20 meters). In addition to work productivity, the user's mental health can also be a factor in user satisfaction. The user's health can be improved by having a comfortable place to spend their break time. Resting in the office is mostly done in the praying room. The users feel more comfortable if it is far from the workspace to reduce noise and to have a higher degree of privacy (20 to 30 meters). The ABO provided sleeping space in the office area. Even though it was far from the workspace, users still went there to rest ( $>60$ meters). Architects or office property owners can use this study's findings to determine the office concept's optimum office layout. The optimum layout can determine the extent of office space to be used under its users' satisfaction.

\section{ACKNOWLEDGMENT}

This article's publication is supported by Universitas Indonesia (UI) through Research Grant: \#NKB1690/UN2.RST/HKP.05.00/2020.

\section{REFERENCES}

[1] Azlan Shah Ali, S. J.-L. (2015). The effect of physical environment comfort on employees' performance in office buildings. Structural Survey, 294-308.

[2] Kerstin Sailer, I. M. (2012). Social networks and spatial configuration-How office layouts drive social interaction. Social Networks, 47-58.

[3] Sarah Zerella, K. (2017). The influence of office layout features on employee perception of organizational culture. Journal of Environmental Psychology, 1-10.

[4] Kwon, M. (2019). Office employee satisfaction: the influence of design factors on psychological user satisfaction. Facilities, 1-19.

[5] Kabo, F. W. (2014). Proximity effects on the dynamics and outcomes of scientific collaborations. Research Policy, 1469-1485.

[6] Agha-Hossein, M. M (2013). Post-occupancy studies of an office environment: Energy performance and occupants' satisfaction. Building and Environment 69, 121-130.

[7] Cordero, A. C (2019). Feel well and do well at work: A postrelocation study on the relationships between employee wellbeing and office landscape. Journal of Corporate Real Estate.

[8] Elmahadi, M. A. (2011). Effective Office Environment Architecture: Finding Ingenious Ideas in a Home to Stimulate the Office Environment. Procedia Engineering, $380-388$.

[9] Petrulaitiene, V. (2015). The perceived value of workplace concepts for organisations. Journal of Corporate Real Estate. 260-281.

[10] Haynes, B. P. (2008). The impact of office layout on productivity. Journal of Facilities Management, 189-201.

[11] Minyoung Kwon, H. R. (2019). Influential design factors on occupant satisfaction with indoor environment in workplaces. Building and Environment, 356-365.
[12] O'Donnell, M. (2019). An expanded holistic model of healthy workplace practices. International Journal of Organizational Analysis, 1542-1561.

[13] Hillier, B., Hanson, J., (1984). The Social Logic of Space. Cambridge University Press, Cambridge, UK.

[14] Brown, M. G. (2008). Proximity and collaboration: measuring workplace configuration. Journal of Corporate Real Estate. 5-26.

[15] Appel-Meulenbroek, R. (2011). An end-user's perspective on activity-based office concepts. Journal of Corporate Real Estate, 122135.

[16] Annu Haapakangas, D. M. (2018). Self-rated productivity and employee well-being in activity-based offices: The role of environmental perceptions and workspace use. Building and Environment, 115-124.

[17] Shahzad, S., Brennan, J., Theodossopoulos, D., Hughes, B. and Calautit, J.K. (2016). Energy and comfort in contemporary open plan and traditional personal offices. Applied Energy 185. 1542-1555.

[18] Gjerland. A., Soiland, E., Thuen, F. (2019). Office concepts: A scoping review. Building and Environment 163. 106294.

[19] Kwon, M., Remoy, H., Dobbelsteen, A., Knaack, U (2019). Personal control and environmental user satisfaction in office buildings: Results of case studies in the Netherlands. Building and Environment 149. $428-435$

[20] Skogland, M.A (2016) The mindset of activity-based working. Journal of Facilities Management 15. 62-75.

[21] Cha, S. H. (2018). Towards a well-planned, activity-based work environment: Automated recognition of office activities using accelerometers. Building and Environment, 86-93.

[22] Hallman, D. M. (2018). Sitting patterns after relocation to activitybased offices: A controlled study of a natural intervention. Preventive Medicine, 384-390.

[23] Rolfö, L. V. (2018). Relocation to an activity-based flexible office Design processes and outcomes. Applied Ergonomics, 141-150.

[24] Hoendervanger, J. G. (2019). Perceived fit in activity-based work environments and its impact on satisfaction and performance. Journal of Environmental Psychology, 1-10.

[25] Beijer, I. D. (2014). The influence of office type on satisfaction and perceived productivity support. Journal of Facilities Management, 142-157.

[26] Neufert, E., \& Neufert, P. (2000). Neufert Architects' Data, Third Edition. Wiley-Blackwell. 348-349.

[27] Zamani, Z., Gum, D., (2018). Activity-based flexible office: Exploring the fit between physical environment qualities and user needs impacting satisfaction, communication, collaboration and productivity. Journal of Corporate Real Estate. 0028.

[28] Ilies, R., Huth, M., Ryan, A.M. and Dimotakis, N. (2015). Explaining the links between workload, distress, and work-family conflict among school employees: physical, cognitive, and emotional fatigue. Journal of Educational Psychology 107. 1136-1149.

[29] Elsbach, K. D., \& Pratt, M. G. (2007). The physical environment in organizations. Academy of Management Annals, 1(1), 181-234.

[30] Zhang, Z., \& Spicer, A. (2014). 'Leader, you first': The everyday production of hierarchical space in a Chinese bureaucracy. Human Relations 67. 739-762 